\title{
Stevia: limiting cholesterol synthesis in Hep-G2 cells
}

\author{
Amirul Nazhan Ilias ${ }^{a}$, Hazilawati Hamzah ${ }^{\mathrm{b}}$, Intan Safinar Ismail ${ }^{\mathrm{c}}$, Mokrish Ajat ${ }^{\mathrm{a}^{*}}$ \\ ${ }^{a}$ Department of Veterinary Preclinical Sciences, Faculty of Veterinary Medicine, Universiti Putra Malaysia, 43400 UPM, Serdang, Selangor \\ Darul Ehsan, Malaysia \\ ${ }^{b}$ Department of Veterinary Pathology \& Microbiology, Faculty of Veterinary Medicine, Universiti Putra Malaysia, 43400 UPM, Serdang, \\ Selangor Darul Ehsan, Malaysia \\ 'Department of Chemistry, Faculty of Science, Universiti Putra Malaysia, 43400 UPM, Serdang, Selangor Darul Ehsan, Malaysia
}

Received 20th November 2019 / Accepted 7th February 2020

\begin{abstract}
As of today, no literature has been reported on the efficacy of stevia on lipid regulations conducted in vitro. Thus, the current study was focusing on the potential of Stevia rebandiana bertoni as an anti-hypercholesterolemia substitute in limiting the de novo cholesterol synthesis in Hep-G2 cell line. The cytotoxicity and lipid internalization effects of stevia on Hep-G2 cells were assessed quantitatively and qualitatively in this study. As evaluated by MTT assay, commercialized stevia $(0.5-20.0 \mathrm{mg} / \mathrm{ml})$ and stevioside $(1.0-10 \mu \mathrm{M})$ inhibited Hep-G2 cells viability in a dose-dependent manner for 24 hours. $\mathrm{IC}_{50}$ was detected at $8.68 \mathrm{mg} / \mathrm{ml}$ (commercialized stevia) and $10.91 \mu \mathrm{M}$ (stevioside). From the assay, suitable concentrations were chosen to study the effect of stevia on cholesterol internalization in Hep-G2 cells supplemented with exogenous lipids. Cholesterol quantification assay revealed that high concentration commercialized stevia and stevioside promoted significant cholesterol internalized in Hep-G2 cells as compared to simvastatin. Finally, immunofluorescent microscopy assessment was done to qualitatively observe the formation of lipid droplets and low-density lipoprotein receptor in relation to total cholesterol extracted. The microphotographs of immunofluorescent microscopy were in parallel to results obtained from the cholesterol quantification assay which further revealed the effect of stevia as a potential antihypercholesterolemia agent.
\end{abstract}

Keywords: anti-hypercholesterolemia, commercialized stevia, lipid droplets, low-density lipoprotein receptor, Stevia rebaudiana bertoni, stevioside

\section{INTRODUCTION}

Plant-derived medicines are considered as an alternative to currently available medicine due to their remarkable potential in terms of pharmacodynamics and pharmacokinetics activities (Lee, 2017). The applications of plantbased medicine have been documented in Egyptian medicine, traditional Chinese medicine, and Indian Ayurveda medicine (Atanasov et al., 2015). Previous in-vitro studies have proven that plant-based medicine derived from Fragaria $x$ ananassa (strawberry), Alpinia galangal (galangal), Phyllanthus emblica (Indian gooseberry), and Ficus carica (common fig) exert anti-hyperlipidemic property to alleviate both cholesterol and triglycerides serum levels (Atyabi et al., 2015; Forbes-Hernández et al., 2017; Tirawanchai et al., 2019). Apart from that, plant-derived components provide antioxidant property capable to neutralize free radicals preventing oxidative damage in the body (Shukla et al., 2012). These

*Author for correspondence: Mokrish Ajat, Department of Biochemistry, Veterinary Preclinical Sciences, Faculty of Veterinary Sciences, Universiti Putra Malaysia, 43400 UPM Serdang, Selangor, Malaysia. Email mokrish@upm.edu.my 
findings have given rise to vast discoveries leading to drug innovation with improved efficiency, lesser side effects to consumers and being commercialized as herbal medicine. Recently, stevia extracts have gained attention in the medical field as a result of its extensiveness in health benefits.

Stevia rebaudiana bertoni, generally known as Stevia is a small perennial herbaceous plant famously utilized as a sugar substitute due to its non-toxic and non-caloric characteristics (Kaur et al., 2014; Sharma et al., 2017; Saniah and Samsiah, 2012). Up to date, there are approximately 230 variations of stevia species available but only $S$. rebaudiana and $S$. phlebophylla are producing glycosides (Ullah et al., 2019). Stevia is native to South America and belongs to the Asteraceae family grows in sandy soils (Siddique et al., 2012; Shukla et al., 2009). The leaves are loaded with flavonoids, phytochemicals, and terpenes that provide immunological protection to the plant against diseases (Jayaraman et al., 2008). Phytochemicals of interest known as steviol glycosides that made up of stevioside, rebaudioside (A, B, C, D, E, and F), and dulcoside presented in the plant at a different amount (Salazar et al., 2018). The two major bioactive components of steviol glycosides; Stevioside and rebaudioside $A$ were found at $5-10 \%$ and $2-4 \%$, respectively that are 200-400 times sweeter than the regular sucrose (Rizwan et al., 2018; Rizzo et al., 2013). Due to their potent sweetness, the extracts are being incorporated in food and beverages to replace sucrose as well as dietary supplements in several countries (Shukla et al., 2009).

Stevia was also reported to play a role as antioxidant, renal protective, anti-tumorigenic, antiinflammatory, reduced atherosclerosis, and promote wound healing (Shivanna et al., 2013; Chen et al., 2018; Greeraert et al., 2010; Das, 2013). Substitution of normal sucrose with stevia is highly recommended for Type- 2 diabetes as it does not induce glycemic response due to the inability of humans to metabolize ingested steviol glycosides (Ullah et al., 2019; Geuns et al., 2007). Prolonged consumption has shown no serious effects, which prove that stevia is non-toxic, noncarcinogenic and non-genotoxic to mammals (Koyama et al., 2003). Although the benefits of stevia extracts have been discussed at length, no reports are available on the regulation of stevia as an anti-hypercholesterolemia agent at the cellular level.

Hyperlipidemia is associated with the elevation of low-density lipoprotein and reduction in circulating high-density lipoprotein (Yang et al., 2019). Hyperlipidemia is a progressive predisposing risk factor to atherosclerosis and coronary heart disease (Maejima et al., 2004). Statin, a HMG-CoA (3-hydroxy-3-methylglutarylcoenzyme A) reductase inhibitors are the most commonly prescribed medicine to patients experiencing hypercholesterolemia (Atyabi et al., 2015). A structurally diverse group of statins are available in the market such as atorvastatin, cerivastatin, fluvastatin, lovastatin, mevastatin, pitavastatin, pravastatin, rosuvastatin and simvastatin to control plasma cholesterol and triglycerides levels (Mashayekhi et al., 2011; Ramkumar et al., 2016). The inhibition of plasma cholesterol levels by HMGCR is well understood.

In the present study, stevia extracts were used to observe the efficiency and efficacy in regulating cholesterol synthesis conducted in-vitro. HepG2 cells were the most suitable in-vitro model for the study because it exhibits a variety of cellular responses to different drugs and involves in cholesterol metabolism (Bao et al., 2012; Levy et al., 2007).

\section{MATERIALS AND METHODS}

\section{Chemicals and reagents}

Human hepatocellular carcinoma (HepG2) cells were purchased from American Type Culture Collection (Rockville, MD, USA). Advanced Minimum Essential Medium (AMEM), 0.25\% Trypsin-EDTA (1X), Fetal Bovine Serum (FBS), Amphotericin-B $(200 \mu \mathrm{g} / \mathrm{ml})$, penicillinstreptomycin $(10,000$ units $/ \mathrm{ml}$ and 10,000 $\mu \mathrm{g} / \mathrm{ml})$, chemically defined (CD) lipid concentrate, low-density lipoprotein (LDL) from human plasma, phosphate-buffered saline (PBS), and Hoechst 33342 were purchased from Gibco, USA. Pierce Bicinchoninic Acid (BCA) protein assay kit was acquired from Merck (Darmstadt, Germany). Dimethyl sulfoxide (DMSO), HPLC grade Simvastatin $(\geq 97 \%)$ and Stevioside hydrate $(\geq 98 \%)$, paraformaldehyde powder $(95 \%)$, 
Thiazol Blue Tetrazolium Bromide (98\%), FluorSave Reagent, and Triton X-100 were obtained from Sigma Aldrich, USA. Commercialized stevia extract in powdered form with $70 \%$ of total glycoside was obtained from Hangzhou Wanray Import \& Export CO., LTD. (China). HPLC grade chloroform, methanol, and hydrochloric acid were purchased from RCI Labscan, Australia. Primary antibody ( $\mathrm{Rb} \mathrm{pAb}$ to LDL Receptor, ab175883), secondary antibody (donkey anti-rabbit IgG, Alexa Fluor 594), and Bodipy 493/503 were purchased from Abcam, UK. Cholesterol Liquicolor was from Human Diagnostic, USA. Bovine serum albumin (BSA) was acquired from Amresco, USA.

\section{Cell culture}

Hep-G2 cell line was thawed and maintained in a $75 \mathrm{~cm}^{2}$ culture flask with 90\% AMEM, supplemented with 10\% FBS, 1\% penicillinstreptomycin and 1\% Amphotericin-B in a humidified incubator at $37^{\circ} \mathrm{C}$ in $5 \% \mathrm{CO}_{2}$. The media was changed every 3 days and passaged every 7 days. Cells were subjected to treatment when the confluency has reached $80-85 \%$.

\section{Stock preparation of commercialized stevia, stevioside and simvastatin}

Commercialized stevia was prepared as a stock solution $(100 \mathrm{mg} / \mathrm{ml})$ in AMEM and vortexed to dissolve the powder completely. The stock solution was syringe filtered using a $0.22 \mu \mathrm{m}$ sterile membrane filter to remove contaminants. Stevioside was dissolved in a sterile DMSO as a stock solution $(1 \mathrm{mg} / \mathrm{ml})$ and aliquoted into glass vials. Simvastatin was activated in ethanol (100\%) followed by $0.1 \mathrm{M}$ sodium hydroxide. Subsequently, the solution was incubated at $50^{\circ} \mathrm{C}$ for 2 hours on a digital dry bath heater and the $\mathrm{pH}$ was adjusted to 7.0 with hydrochloric acid.

\section{Cytotoxicity determination of commercialized stevia and stevioside on Hep-G2 cells}

Cells were propagated in a 96-well microplate at a density of $1 \times 10^{4}$ cells per well and allowed to grow overnight. Hep-G2 cells were supplemented with commercialized stevia $(0.5,1.0,2.0,5.0,10.0$ and $20.0 \mathrm{mg} / \mathrm{ml}$ ) and stevioside (1.0, 2.0, 2.5, 5.0 and $10.0 \mu \mathrm{M})$ for 24 hours. The following day, supplemented media was removed and cells were further incubated with MTT reagent $(5 \mathrm{mg} / \mathrm{ml})$ for 3 hours at $37^{\circ} \mathrm{C}$ in $5 \% \mathrm{CO}_{2}$. DMSO was added into each well and the plate was placed on an orbital shaker for 15 minutes to dissolve the formazan crystals formed. Absorbance was measured at $570 \mathrm{~nm}$ using a spectrophotometer (Infinite ${ }^{\circledR}$ M200 Pro Tecan, Switzerland). The mean absorbance of commercialized stevia and stevioside treated cells was compared to the mean absorbance of untreated cells (AMEM only). The half-maximal inhibitory concentration $\left(\mathrm{IC}_{50}\right)$ was determined as follows:

$\left(\mathrm{IC}_{50}\right)=$ Average $\mathrm{A}_{570 \mathrm{~nm}}$ Treated Group / Average $A_{570 \mathrm{~nm}}$ Control Group x 100\%

From the calculation, concentration exhibiting $30 \%$ less cytotoxic effects $(<70 \%$ viability) towards the cells were used in cholesterol quantification assay and immunofluorescence microscopy to further validate the effectiveness of commercialized stevia and stevioside on the internalization of cholesterol in Hep-G2 cells.

\section{Quantification of cholesterol mobilized into HepG2 Cells}

To quantify the amount of cholesterol uptake by Hep-G2 cells supplemented with commercialized stevia and stevioside, lipid extraction according to Bligh and Dyer method was adapted (Bligh and Dyer, 1959). Hep-G2 cells at passage 20 were seeded in a 6 -wells culture plate with $0.3 \times 10^{6}$ cells suspended in $2 \mathrm{ml}$ media per well and incubated overnight in $5 \% \mathrm{CO}_{2}$ at $37^{\circ} \mathrm{C}$.

The complete growth media was discarded and replaced with supplemented media prepared accordingly: a) baseline control; AMEM and FBS, b) negative control; AMEM, FBS, and CD lipid concentrate c) positive control; AMEM, FBS, CD lipid concentrate, and $4 \mu \mathrm{M}$ simvastatin, d) low-concentration commercialized stevia; AMEM, FBS, CD lipid concentrate, and 0.5 $\mathrm{mg} / \mathrm{ml}$ commercialized stevia, e) highconcentration commercialized stevia; AMEM, FBS, CD lipid concentrate, and $5.0 \mathrm{mg} / \mathrm{ml}$ commercialized stevia, f) low-concentration stevioside; AMEM, FBS, CD lipid concentrate, and $1.0 \mu \mathrm{M}$ stevioside, and g) highconcentration stevioside; AMEM, FBS, CD lipid concentrate, and $5.0 \mu \mathrm{M}$ stevioside. 
After incubation for 24 hours, Hep-G2 cells were washed twice with sterile, cold PBS to inhibit any further metabolism in cells. The cells were then mechanically detached using a cell scraper, rinsed with $1 \mathrm{ml}$ sterile PBS and collected in a $5 \mathrm{ml}$ centrifuge tube. Hep-G2 cells were homogenized using Sonic Dismembrator (Thermo Fisher Scientific, USA) for 10 seconds at $20 \%$ amplitude on ice. Then, $800 \mu \mathrm{l}$ of homogenized cells were transferred to a glass tube and subjected to lipid extraction. Cholesterol quantification was determined by cholesterol assay kit according to the manufacturer's instruction and absorbance was taken at $540 \mathrm{~nm}$ wavelength using a spectrophotometer. The absorbance was calculated as follow:

Cholesterol concentration $(\mathrm{mmol} / \mathrm{L})=5.17 \mathrm{x}$ [(Average Treated Group $A_{540 \mathrm{~nm}} /$ Average Blank $\left.\left.A_{540 \mathrm{~nm}}\right)\right] /$ [(Average Standard $A_{540 \mathrm{~nm}} /$ Average Blank A540 nm) ]

\section{Assessment of lipid droplets (LDs) and Low- density lipoprotein receptor (LDL-r) in Hep- G2 cells}

For immunofluorescence microscopy, cells were cultured on a round-glass coverslip placed in 4wells cell culture plate at $1 \times 10^{3}$ cells in $2 \mathrm{ml}$ of complete growth media per well. Cells were allowed to grow overnight in $5 \% \mathrm{CO}_{2}$ at $37^{\circ} \mathrm{C}$. The following day, cells were supplemented in the same manner as in lipid quantification and incubated for another 24 hours.

After incubation, Hep-G2 cells were fixed with 4\% paraformaldehyde in PBS and rinsed three times using cold PBS. Cells were blocked and permeabilized with $2 \%$ BSA and $0.2 \%$ Triton X-100 prepared in PBS. Subsequently, cells were rinsed three times with PBS for five minutes in each washing and incubated with primary antibody (1:50) for 1 hour. Hep-G2 cells were further incubated with secondary antibody $(1: 200)$ and counterstained with Bodipy 493/503 (1:50) for lipid droplets and Hoechst 33342 (1:50) for nucleus. Coverslips were mounted on a glass slide using Fluorsave and observed using an inverted fluorescence microscope (Nikon Eclipse Ti-S, Japan).

\section{Data analysis}

To determine the $\mathrm{IC}_{50}$ of commercialized stevia and stevioside, mean absorbance values were used to plot the cytotoxicity curve. For the cholesterol quantification assay, One-way ANOVA was used for data analysis by comparing groups against positive control (PC). P-value $<0.05$ is considered as significant differences. The values were reported as the mean and standard deviation. Data analysis was performed using the GraphPad Prism version 7 for Windows, GraphPad Prism (USA).

\section{RESULTS}

\section{Cytotoxic effect of commercialized stevia and stevioside on Hep-G2 Cells}

The assay yielded various results between controlled cells against cells supplemented with either commercialized stevia or stevioside. In Figure 1 (A-B), both commercialized stevia and stevioside markedly inhibited the proliferation rate of Hep-G2 cells in a dose-dependent manner. The $\mathrm{IC}_{50}$ of commercialized stevia on Hep-G2 cells was observed at $8.68 \mathrm{mg} / \mathrm{ml}$ and stevioside at $10.91 \mu \mathrm{M}$. A suitable range of concentration was established from the assay: commercialized stevia $(0.5 \mathrm{mg} / \mathrm{ml}$ and $5.0 \mathrm{mg} / \mathrm{ml})$ and stevioside $(1.0 \mu \mathrm{M}$ and $5.0 \mu \mathrm{M}$ ) as more than $70 \%$ of cells were alive at these concentrations. These concentrations were further supplemented to Hep-G2 cells in cholesterol assay quantification and immunofluorescence microscopy evaluation.

\section{Internalization of cholesterol in Hep-G2 cells} Cholesterol quantification assay was performed by supplementing Hep-G2 cells with commercialized stevia $(0.5 \mathrm{mg} / \mathrm{ml}$ and 5.0 $\mathrm{mg} / \mathrm{ml})$ and stevioside $(1.0 \mu \mathrm{M}$, and $5.0 \mu \mathrm{M})$ determined from the previous MTT assay. Figure 2 shows the cholesterol concentration of controls (BC, NC, and PC) and supplemented cells with $0.5 \mathrm{mg} / \mathrm{ml}$ commercialized stevia (low CS), 5.0 $\mathrm{mg} / \mathrm{ml}$ commercialized stevia (high CS), $1.0 \mu \mathrm{M}$ stevioside (low STV), and $5.0 \mu \mathrm{M}$ stevioside (high STV) were normalized with protein concentration quantified by the BCA protein determination assay earlier. Data were compared to positive control (PC). In general, BC showed 
the least amount of total cholesterol stored in cells followed by NC, Low CS, PC, Low STV, High CS, and High STV. Cells supplemented with high CS $(5.0 \mathrm{mg} / \mathrm{ml})$ and high STV $(5.0 \mu \mathrm{M})$ promotes cholesterol mobilization with significant results as compared to PC.

\section{Immunofluorescence (IF) imaging}

Immunofluorescence signals for nuclei, lipid droplets (LDs), and low-density lipoprotein receptor (LDLr) were obtained by fluorescence microscopy. These signals were detected accordingly: nuclei (blue), LDs (green), and LDLr (red). In Figure 3, presence of LDs (green) and LDLr (red) were expressed at different degrees between samples. Generally, the exact visualization of these structures remains elusive in regard to their distribution. However, the expression of these signals qualitatively in parallel with the total cholesterol quantified from the assay conducted earlier. In general, cells supplemented with high concentration of stevioside $(5.0 \mu \mathrm{M})$ showed a significant fluorescent intensity of LDs and LDLr as compared to all controls.
A

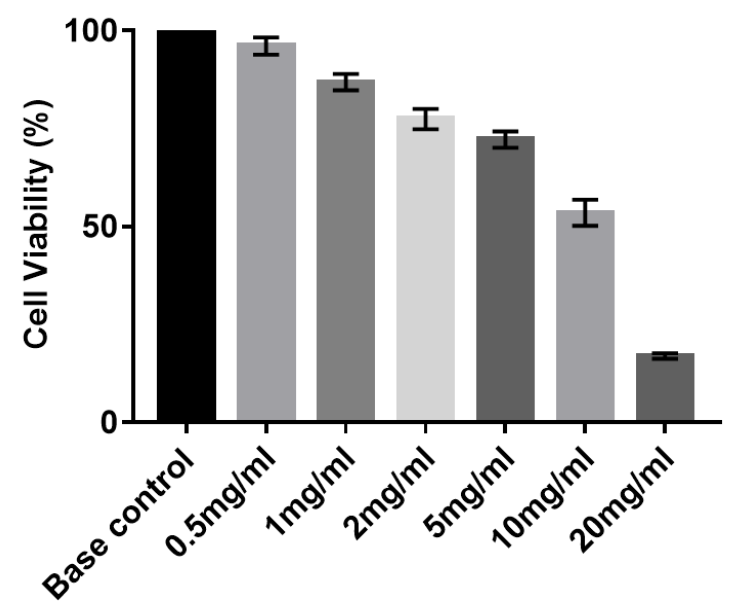

B

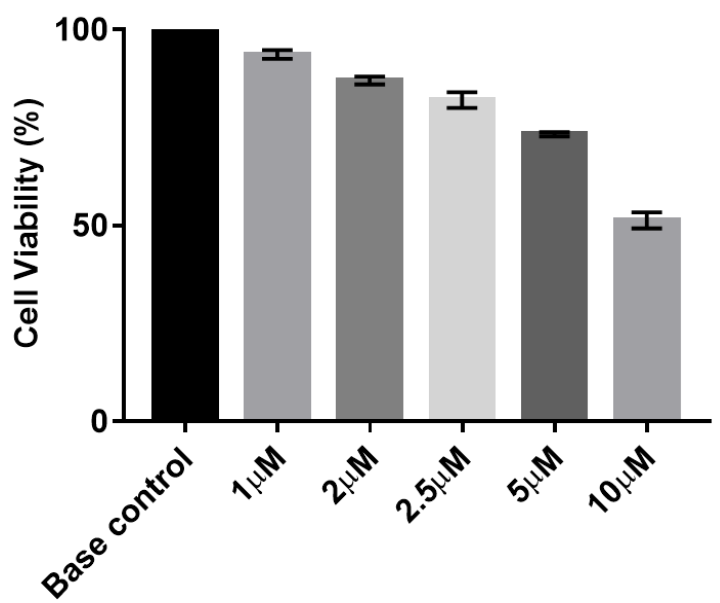

Figure 1. Viability profiles of Hep-G2 cells supplemented with (A) commercialized stevia and (B) stevioside followed by 24 hours incubation at different concentrations. The viability of the control was $100 \%$ viable cells $(n=6)$.

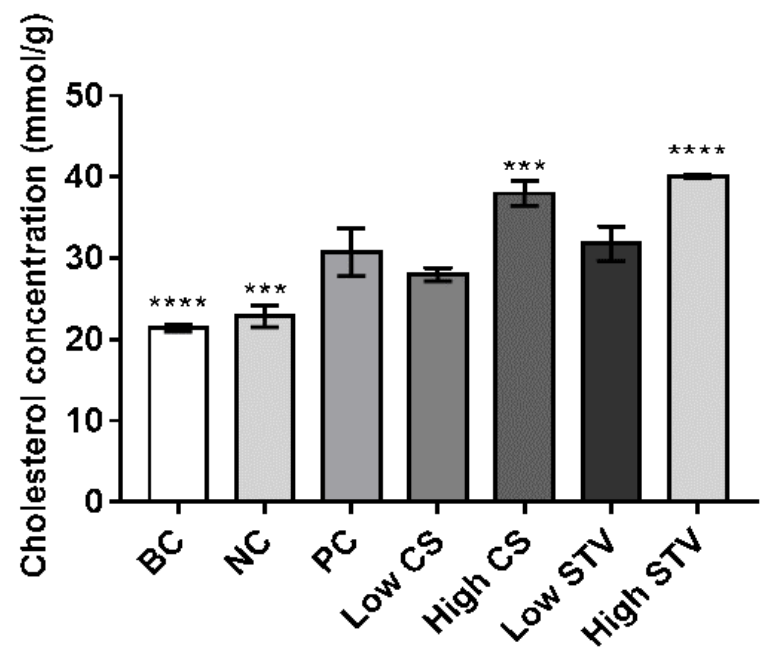

Figure 2. Total cholesterol concentration $(\mathrm{mmol} / \mathrm{g})$ of BC $(21.45 \pm 0.46)$, NC $(22.86 \pm 0.79)$,

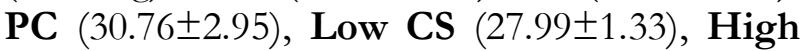
CS (37.98 \pm 1.53$)$, Low STV (31.79 \pm 2.14$)$, and High STV (40.07 \pm 0.19$)$. $(\mathrm{n}=3)$. 

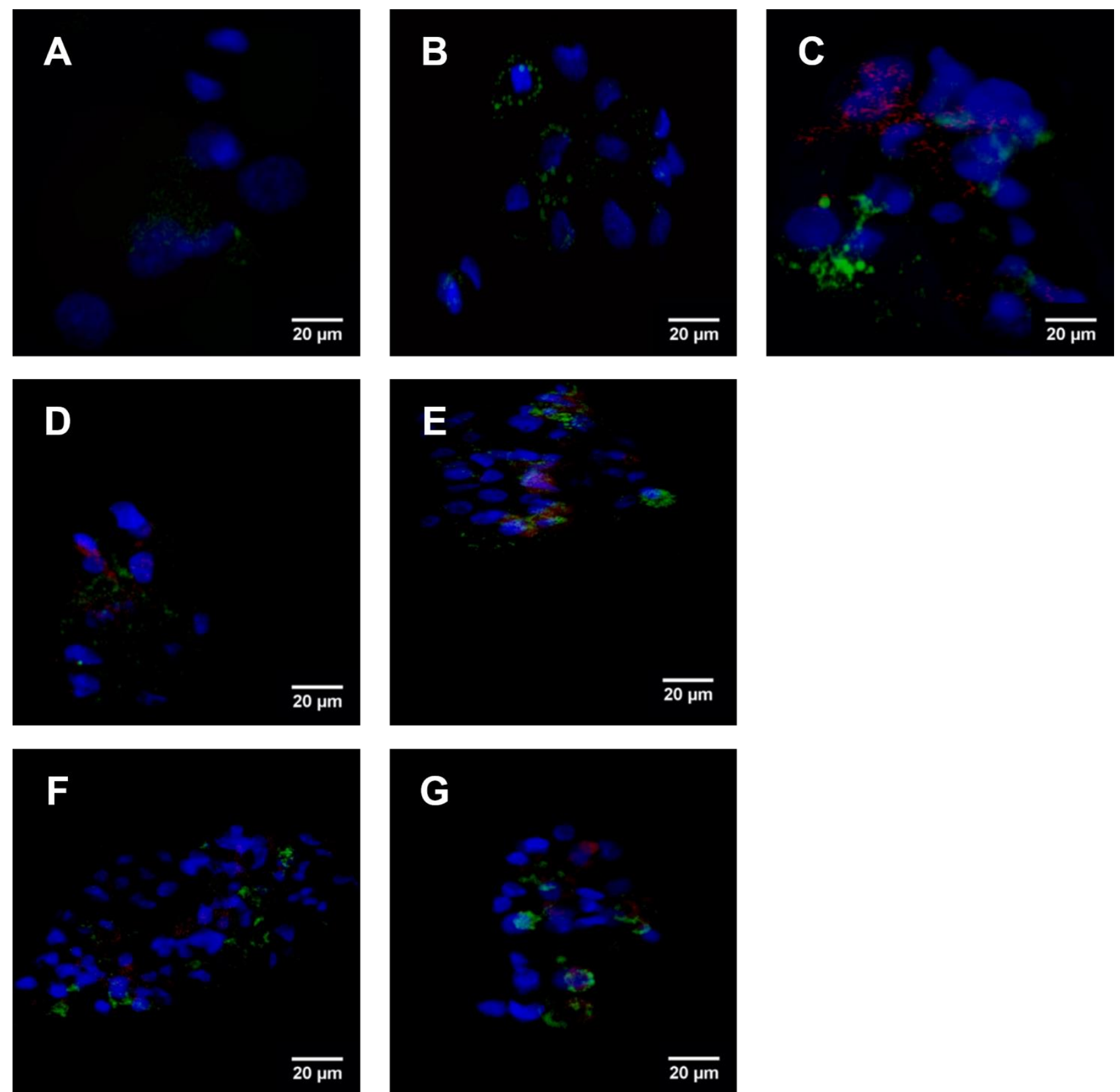

Figure 3. Presence of nuclei, lipid droplets (LDs), and low-density lipoprotein (LDL-r) on Hep-G2 cells post 24 hours incubation with (A) baseline control, (B) negative control, (C) positive control, (D) commercialized stevia $0.5 \mathrm{mg} / \mathrm{ml},(\mathbf{E})$ commercialized stevia $5.0 \mathrm{mg} / \mathrm{ml},(\mathbf{F})$ stevioside $1.0 \mu \mathrm{M}$, and $(\mathbf{G})$ stevioside $5.0 \mu \mathrm{M}$ were observed at $20 \mathrm{X}$ magnification using an inverted immunofluorescence microscopy (scale bar: $20 \mu \mathrm{m}$ ). Nuclei, LDs, and LDL-r were detected by blue (Hoechst 33342), green (BODIPY 493/503) and red (Alexa Fluor 594) fluoresced structures, accordingly.

\section{DISCUSSION}

Globally, cardiovascular disease (CVD) contributes up to 17 million mortality cases per year caused by the alteration of normal lipoprotein metabolism (Blesso et al., 2018;
Forbes-Hernández et al., 2017). The altered lipoprotein metabolism involving low-density lipoprotein (LDL), high-density lipoprotein (HDL), and triglycerides (TG) is termed as dyslipidemia (Kolovou et al., 2005). Elevation of plasma cholesterol specifically LDL coupled with a decrease in HDL are the predisposing factors to 
atherosclerosis and other cardiovascular-related diseases (Yang et al., 2019). Atherosclerosis is a pathological condition whereby the normal structure of the arterial intima becomes asymmetrically narrowed as a result of atherosclerotic plaques formation (Wang et al., 2017). The condition could affect either large or medium-sized arteries and the clinical signs are undetected until thrombosis occurred, which leads to other complications (Abdolmaleki et al., 2019). Precursor attributed to atherosclerosis is the deterioration of the endothelial lining and oxidization of progressively accumulated LDL particles along the arterial walls (Moriya, 2019).

Currently, statin therapy is effective in lowering LDL-cholesterol (20-50\%), as well as triglyceride (10-20\%) and increasing serum HDLcholesterol levels (5-10\%) (Ramkumar et al., 2016). Pharmacodynamic of statin involves the inhibition of de novo cholesterol synthesis by competitively blocking HMG-CoA reductase. This rate-limiting enzyme catalyzes the conversion of HMG-CoA to mevalonate, the initial step in cholesterol production (Tirawanchai et al., 2019). Apart from suppressing hepatic cholesterol synthesis, statins aid in the upregulation of hepatocellular LDL-r resulting in scaling down the LDL-cholesterol level (Funatsu et al., 2001).

Although it is well known that statins are competent in alleviating atherogenic lipoprotein plasma level (20-50\%) and triglycerides (10-20\%), potential adverse effects are unavoidable (Mullen et al., 2010; Ramkumar et al., 2016). Documented reports on patients experiencing dose-dependent adverse effects of statins such as myositis, myalgia, persistent muscle effects, rhabdomyolysis, headache, liver failure, and gastrointestinal related problems (Golomb et al., 2008; Mashayekhi et al., 2011). Together with adverse effects varying from rare to lifethreatening, the cost-effectiveness on types of statins is also a concern (Morrison and Glassberg, 2003).

This study focuses on the effects of stevia as a cholesterol-lowering agent on Hep-G2 cell line supplemented with exogenous lipids. To be developed as an alternative medicine, determination on the half-maximal inhibitory concentration $\left(\mathrm{IC}_{50}\right)$ is important as it provides valuable information pertaining to the cytotoxic effects of a supplement on the targeted cell. These effects range from the destruction of the structural integrity of cells to altering their metabolic activities (Aslantürk, 2017). To achieve this objective, MTT (3-(4, 5-dimethylthiazol-2-yl)2, 5-diphenyltetrazolium bromide) tetrazolium reduction assay was conducted. MTT is a reliable, reproducible, and economical method used to determine the viability of cells concerning their metabolic activities (Sharma et al., 2019). Hep-G2 cells were supplemented with different concentrations of commercialized stevia and stevioside for 24 hours to assess the immediate response of cells (acute toxicity).

As shown in Figure 1 (A), the $\mathrm{IC}_{50}$ of commercialized stevia was determined at 8.68 $\mathrm{mg} / \mathrm{ml}$. From the results, supplements that inhibit cell viability less than $30 \%$ were chosen further studies. Previous study has reported a significant inhibition of Hep-G2 cell growth observed when the concentration of extracted stevia is at 12.5 $\mathrm{mg} / \mathrm{ml}$ (Jayaraman et al., 2008). The slight difference of $\mathrm{IC}_{50}$ could be due to the presence of steviol glycosides percentages in the commercialized product and the solvent used. According to the guidelines by FDA and EFSA, stevia extracts must contain at least $95 \%$ of steviol glycosides (Rizwan et al., 2018). In this study, the content of steviol glycosides in commercialized stevia was $70 \%$ while the remaining was suspected to be adulterant which could be a reason to low $\mathrm{IC}_{50}$ determined from the current study. Such adulterant was not disclosed by the supplier or the material safety data sheet.

As for stevioside, a significant cytotoxic effect was determined at $10.91 \mu \mathrm{M}$ on Hep-G2 cells. Our current findings is in agreement with the $\mathrm{IC}_{50}$ of stevioside supplemented to MCF-7 cell line was found to be in a range between 10-20 $\mu \mathrm{M}$ (Paul et al., 2012). Observation of 24 hours supplementation of stevioside $(5 \mu \mathrm{M})$ on HT-29 colon cancer cells significantly inhibited the viability of cells (Ren et al., 2017). However, a higher concentration of stevioside $(>200 \mu \mathrm{M})$ is required to induce cytotoxicity in HCT 116 cell and CCD18 Co cells (Sharif et al., 2017). Thus, we can conclude that the resistance of cell lines towards a supplement is different due to several factors. These factors are: 1) the molecular size of the tested compound, 2) genetic variation and composition of the targeted cell, 3) alteration of 
the cells internal environment, and 4) the mechanisms of the targeted cells (Sharif et al., 2017). From our findings, $1.0 \mu \mathrm{M}$ and $5.0 \mu \mathrm{M}$ of stevioside were used in further experiments as more than $70 \%$ of cells were viable at these concentrations.

Aforementioned, commercialized stevia (0.5 $\mathrm{mg} / \mathrm{ml}$ and $5.0 \mathrm{mg} / \mathrm{ml})$ and stevioside $(1.0 \mu \mathrm{M}$ and $5.0 \mu \mathrm{M}$ ) were supplemented to cells in cholesterol quantification assay. Simvastatin, a HMG-CoA reductase inhibitors served as a positive control in this study was supplemented to cells at $10 \mu \mathrm{M}$ due to its $\mathrm{IC}_{50}$ on Hep-G2 cells (Janine et al., 2012). Inhibition of de novo cholesterol synthesis in sample-treated simvastatin is well understood. We hypothesized that a similar effect has taken place in Hep-G2 cells supplemented with commercialized stevia and stevioside. Total cellular cholesterol concentrations were measured to determine the effectiveness of these two supplements in inhibiting the pathway of interest.

Apart from the high proliferation rate (Maria et al., 2015), Hep-G2 cell line was used in this study as majority of cholesterol metabolism takes place in the liver in particularly the hepatocytes. Cholesterol quantification assay revealed that cells supplemented with stevioside $(5 \mu \mathrm{M})$ treated cells has the highest cholesterol concentration ( $\mathrm{mmol} / \mathrm{g}$ ) followed by commercialized stevia (5 $\mathrm{mg} / \mathrm{ml}$ ). It is important to emphasize that no study has been conducted to evaluate the efficacy of stevia as a hypolipidemic agent in in-vitro. Most findings were reported on the in-vivo model with similar results as in the current study in which stevia helps to improve the serum lipid level. The lipid profile in stevioside-supplemented rats was improved as the total cholesterol, triglyceride, LDL-C, and VLDL lowered with an increment of HDL-C level (Elnaga et al., 2016). To further support the findings, evaluation of the oral intake of stevia extracts caused a reduction of serum cholesterol $(240.5 \mathrm{mg} / \mathrm{dl}$ to $229.55 \mathrm{mg} / \mathrm{dl})$ in humans (Sharma et al., 2017).

Among the control, simvastatin at $10 \mu \mathrm{M}$ (PC) was proven to be effective in lipid internalization into cells. Surprisingly, cholesterol assay on BC sample yielded $21.45 \mathrm{mmol} / \mathrm{g}$ of cholesterol despite the absence of exogenous lipids/cholesterol in media. However, this could be explained as total cholesterol extracted from
BC was contributed by albumin-bound cholesterol found in the FBS (Okonkowski et al., 2007). To further confirm the results from cholesterol quantification assay, Hep-G2 cells supplemented in the same manner were subjected for immunofluorescence microscopy.

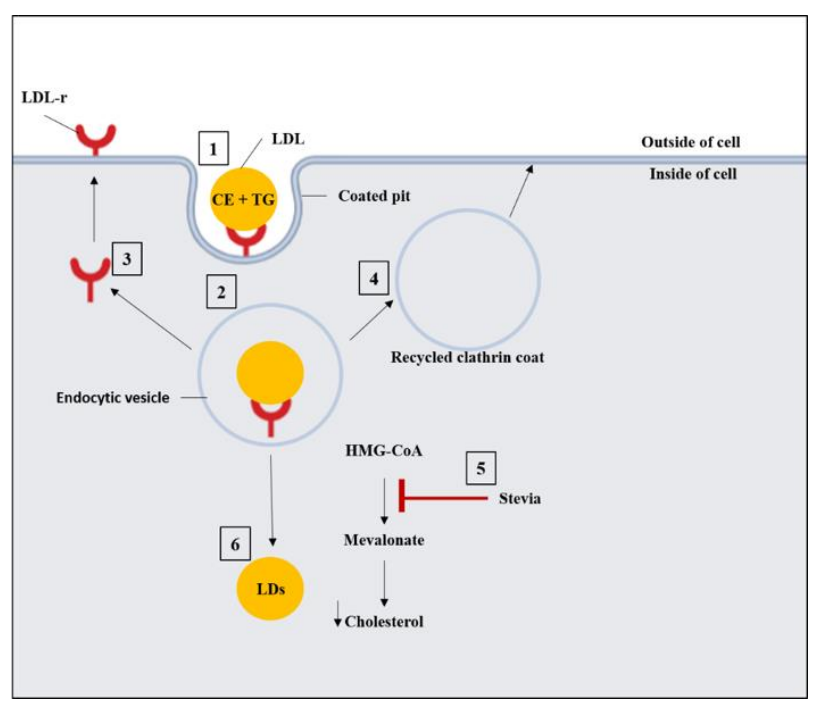

Figure 4. Proposed pathway of stevia in the inhibition of the mevalonate pathway. Stevia has potential anti-hypercholesterolemia property as it inhibits the 3-hydroxy-3-methylglutaryl-CoAreductase (HMGCR). 1) LDL binds to LDL-r located on the cell surface. 2) LDL and LDL-r are then internalized into the hepatocyte in the clathrin-coated vesicle. 3\&4) LDL-r and clathrincoated vesicles are dissociated from the LDL and recycled back to the cell surface by endosome. 5) Lysosome degraded cholesteryl ester (CE) and triglycerides (TG) to amino acid and cholesterol. 5) Stevia prevents the conversion of $\mathrm{HMG}-\mathrm{CoA}$ to mevalonate and lower the endogenous cholesterol synthesis by 6 ) promoting the storage of cholesterol in the form of lipid droplets (LDs).

Qualitative observation on IF microphotographs off supplemented cells revealed that high concentration of commercialized stevia and stevioside regulates the formation of LDLr (red fluorescent) as well as LDs (green fluorescent). LDs are organelles involved in excessive neutral lipid (lipid ester core surrounded by phospholipid monolayer) storage of cells (Guo et al., 2009; Suzuki et al., 2011). Meanwhile, LDLr is a receptor for low-density lipoprotein (LDL) localized on cell surface. Briefly, we hypothesized that these supplementations up-regulate the 3-hydroxy- 
3methylglutarate-CoA reductase (HMGCR) at the molecular level. The up-regulation of HMGCR will eventually inhibit the mevalonate pathway in the de novo cholesterol synthesis. The inhibition of this enzyme is an effective indicator of lowering circulating cholesterol as it is the main target of commonly used in lipid-lowering medication. Figure 4 depicted the proposed pathway of stevia in regulating cholesterol de novo synthesis.

\section{CONCLUSION}

In conclusion, it is well known that statins are currently prescribed as anti-hypercholesterolemia drugs as they are highly effective in regulating blood cholesterol levels. However, considering the multiple rare to life-threatening adverse effects, alternative way to replace statins is important. The present study revealed that stevia has the potential to be applied as a cholesterollowering drug. However, additional studies are required to further verify how stevia extracts exert anti-hypercholesterolemia property at the cellular and molecular level.

\section{ACKNOWLEDGEMENTS}

This research was funded by the Universiti Putra Malaysia and Faculty of Veterinary Medicine (UPM). Also, we would like to acknowledge Mr. Mohd. Jamil Samad from the Equipment Lab, Faculty of Veterinary Medicine (UPM) for his guidance in immunofluorescence microscopy viewing.

\section{REFERENCES}

Abdolmaleki, F., Hayat, S. M. G., Bianconi, V., Johnston, T. P., \& Sahebkar, A. 2019. Trends in cardiovascular medicine atherosclerosis and immunity: a perspective. Trends in Cardiovascular Medicine 29(2019): 363-371.

Aslantürk, Ö.S. 2017. In vitro cytotoxicity and cell viability assays: principles, advantages, and disadvantages. In GenotoxicityA predictable risk to our actual world. (London, UK). IntechOpen, pp. 1-19.

Atanasov, A. G., Waltenberger, B., Pferschy-wenzig, E., Linder, T., Wawrosch, C., Uhrin, P., \& Stuppner, H. 2015. Discovery and resupply of pharmacologically active plant-derived natural products: a review. Biotechnology Advances 33(8): 1582-1614.

Atyabi, N., Asadian, P., Asadi, F., \& Pourkabir, M. 2015. Alterations of triglyceride and cholesterol in response to Aloe vera gel extract in HepG2 cells and hyperlipidemic guinea pigs. International Journal of Veterinary Research 4(3): 153-158.

Bao, S. R., Ge, X. Z., \& Lian, Y. H. 2012. Cytotoxicity and apoptosis induction in human HepG2 hepatoma cells by decabromodiphenyl ethane. Biomedical and Environmental Sciences 25(5): 495-501.

Blesso, C. N., \& Fernandez, M. L. 2018. Dietary cholesterol, serum lipids, and heart disease: Are eggs working for or against you? Nutrients 10(4): 1-12.

Bligh, E. G. and Dyer, W. J. 1959. A rapid method of total lipid extraction and purification. Canadian Journal of Biochemistry and Physiology 37(8): 911-917.

Chen, J. M., Zhang, J., Xia, Y. M., Wang, X. X., \& Li, J. 2018. The natural sweetener metabolite steviol inhibits the proliferation of human osteosarcoma U2OS cell line. Oncology Letters 15(2018): 5250-5256.

Das, K. 2013. Wound healing potential of aqueous crude extract of Stevia rebaudiana in mice. Revista Brasileira de Farmacognosia - Brazilian Journal of Pharmacognosy 23(2): 351-357.

Elnaga, N. I. E. A., Massoud, M. I., Yousef, M. I., \& Mohamed, H. H. A. 2016. Effect of stevia sweetener consumption as noncaloric sweetening on body weight gain and biochemical's parameters in overweight female rats. Annals of Agricultural Sciences 61(1): 155-163.

Forbes-Hernández, T. Y., Giampieri, F., Gasparrini, M., Afrin, S., Mazzoni, L., Cordero, M. D., Mezetti, B., Quiles., L. J., \& Battino, M. 2017. Lipid accumulation in HepG2 Cells is attenuated by strawberry extract through AMPK activation. Nutrients 9(621): 1-19.

Funatsu, T., Suzuki, K., Goto, M., Arai, Y., Kakuta, H., Tanaka, H. Yasuda, S., Ida, M., Nishijima, S., \& Miyata, K. 2001. Prolonged inhibition of cholesterol synthesis by atorvastatin inhibits apo B-100 and triglyceride secretion from HepG2 cells. Atherosclerosis 157: 107-115.

Geeraert, B., Crombe, F., Hulsmans, M., Benhabiles, N., Geuns, J. M., \& Holvoet, P. 2010. Stevioside inhibits atherosclerosis by improving insulin signaling and antioxidant defense in obese insulin-resistant mice. International Journal of Obesity 34: 569-577.

Geuns, J. M. C., Buyse, J., Vankeirsbilck, A., \& Temme, E. H. M. 2007. Metabolism of stevioside by healthy subjects. Experimental Biology and Medicine 232(1): 164-173.

Golomb, B. A., \& Evans, M. A. 2008. Statin adverse effects: A review of the literature and evidence for a mitochondrial mechanism. American Journal of Cardiovascular Drugs 8(6): 373-418.

Guo, Y., Cordes, K. R., Farese, R. V, \& Walther, T. C. 2009. Lipid droplets at a glance. Journal of Cell Science 122: 749-752.

Janine, K., Andrea, W., Amelia, D.K., Husevin, S., Roberta, M., Matthias, O., Tassilo, V., Maura, D., Gisa, T., \& Gabrielle, S. 2012. Selective induction of apoptosis by HMG-CoA reductase inhibitors in hepatoma cells and dependence on p53 expression. Oncology Reports 28: 1077-1083.

Jayaraman, S., Manoharan, M. S., \& Illanchezian, S., 2008. In-vitro antimicrobial and antitumor activities of Stevia Rebaudiana (Asteraceae) leaf extracts. Tropical Journal of Pharmaceutical Research 7(4): 1143-1149.

Kaur, G., Pandhair, V., \& Cheema, G. S. 2014. Extraction and characterization of steviol glycosides from Stevia rebaudiana bertoni leaves. Journal of Medicinal Plant Studies 2(5): 41-45.

Kolovou, G. D., Anagnostopoulou, K. K., \& Cokkinos, D. V. 2005. Pathophysiology of dyslipidaemia in the metabolic syndrome. Postgraduate Medical Journal 81(2005): 358-366. 
Koyama, E., Kitazawa, K., Ohori, Y., Izawa, O., Kakegawa, K., Fujino, A., \& Ui, M. 2003. In vitro metabolism of the glycosidic sweeteners, stevia mixture and enzymatically modified stevia in human intestinal microflora. Food and Chemical Toxicology 41(3): 359-374.

Lee, J.-Y. 2008. Pharmacodynamic and pharmacokinetic interactions between herbs and western drugs. Oriental Pharmacy and Experimental Medicine 8(3): 207-214.

Levy, E., Spahis. S., Sinnet, D., Peretti, N., Maupas-Schwalm, F., Delvin, E., Lambert, M., \& Lavoie, MA. 2007. Intestinal cholesterol transport proteins: an update and beyond. Current Opinion in Lipidology 18: 310-318.

Maejima, T., Yamazaki, H., Aoki, T., Tamaki, T., Sato, F., Kitahara, M., \& Saito, Y. 2004. Effect of pitavastatin on apolipoprotein A-I production in HepG2 cell. Biochemical and Biophysical Research Communication 324(2004): 835-839.

Maria, T. D., Laia, T., \& Maria, J. G. L. 2015. Culture and functional characterization of human hepatoma HepG2 cells. Protocols in In Vitro Hepatocyte Research 1250: 77-93.

Mashayekhi, S. O., Ghandforoush-Sattari, M., Baghdadchi, M. E., \& Kheyri, M. 2011. Patients' report of statins use and sideeffects in a sample of hospitalized cardiac patients in the Islamic Republic of Iran. Eastern Mediterranean Health Journal 17(5): 460-464.

Moriya, J. 2019. Critical roles of inflammation in atherosclerosis. Journal of Cardiology 73(1): 22-27.

Morrison, A., \& Glassberg, H. 2003. Determinants of the costeffectiveness of statins. Journal of Managed Care Pharmacy 9(6): 544-551.

Mullen, P. J., Lüscher, B., Scharnagl, H., Krähenbühl, S., \& Brecht, K. 2010. Effect of simvastatin on cholesterol metabolism in C2C12 myotubes and HepG2 cells, and consequences for statin-induced myopathy. Biochemical Pharmacology 79(8): 1200-109.

Okonkowski, J., Balasubramanian, U., Seamans, C., Fries, S., Zhang, J., Salmon, P., Robinson, D., \& Chartrain, M. 2007. Cholesterol delivery to NS0 cells: Challenges and solutions in disposable linear low-density polyethylene-based bioreactors. Journal of Bioscience and Bioengineering 103(1): 50 59.

Paul, S., Sengupta, S., Banyopadhyay, T. K., \& Bhattacharyya, A. 2012. Stevioside induced ROS-mediated apoptosis through mitochondrial pathway in human breast cancer cell line MCF-7. Nutrition and Cancer 64(7): 1087-1094.

Ramkumar, S., Raghunath, A., \& Raghunath, S. 2016. Statin therapy: review of safety and potential side effects. Acta Cardiologica Sinica 32: 631-639.

Ren, X., Zhao, X., Turcotte, F., Deschênes, J. S., Tremblay, R., \& Jolicoeur, M. 2017. Current lipid extraction methods are significantly enhanced adding a water treatment step in Chlorella protothecoides. Microbial Cell Factories 16(26): 1-13.

Rizwan, F., Rashid, H. U., Yesmine, S., Monjur, F., \& Chatterjee, T. K., 2018. Preliminary analysis of the effect of Stevia (Stevia rebaudiana) in patients with chronic kidney disease (stage I to stage III). Contemporary Clinical Trials Communications 12(2018): 17-25.

Rizzo, B., Zambonin, L., Angeloni, C., Leoncini, E., Sega, F. V. D., Prata, C., Fiorentini, D., \& Hrelia, S. 2013. Steviol glycosides modulate glucose transport in different cell types. Oxidative Medicine and Cellular Longevity 2013: 1-12.

Salazar. V. A. G., Encalada, S. V., \& Cruz, A. C. 2018. Stevia rebaudiana: A sweetener and potential bioactive ingredient in the development of functional cookies. Journal of Functional Foods 44: 183-190.

Saniah, K., \& Samsiah, M. S. 2012. The application of Stevia as sugar substitute in carbonated drinks using response surface methodology. Journal of Tropical Agriculture and Food Science 40(1): 23-34.
Sharif, R., Chan, K. M., Ooi, T. C., \& Mohammad, N. F. 2017. Cytotoxicity and genotoxicity evaluation of stevioside on CCD18Co and HCT 116 cell lines. International Food Research Journal 24(1): 341-345.

Sharma, N., Arya, G., Kumari, M., Gupta, N., \& Nimesh, S. 2019. Evaluation of anticancer activity of silver nanoparticles on the A594 human lung carcinoma cell lines through alarm blue assay. Bio-protocol 9(1): 1-9.

Sharma, N., Mogra, R., \& Upadhyay, B. 2017. Effect of stevia extract intervention on lipid profile. Studies on Ethno-Medicine 3(2): 137-140

Shivanna, N., Naika, M., Khanum, F., \& Kaul, V. K. 2013. Antioxidant, anti-diabetic and renal protective properties of Stevia rebaudiana. Journal of Diabetes and Its Complications 27(2): 103-113.

Shukla, S., Mehta, A., Mehta, P., \& Bajpai, V. K. 2012. Antioxidant ability and total phenolic content of aqueous leaf extract of Stevia rebaudiana Bert. Experimental and Toxicologic Pathology 64(7-8): 807-811.

Shukla, S., Mehta, A., Mehta, P., \& Bajpai, V. K. 2009. In vitro antioxidant activity and total phenolic content of ethanolic leaf extract of Stevia rebaudiana Bert. Food and Chemical Toxicology 47(9): 2338-2343.

Siddique, A. B., Rahman, S. M. M., \& Hossain, M. A. 2012. Chemical composition of essential oil by different extraction methods and fatty acid analysis of the leaves of Stevia Rebaudiana Bertoni. Arabian Journal of Chemistry 9(2016): S1185-S1189.

Suzuki, M., Shinohara, Y., Ohsaki, Y., \& Fujimoto, T. 2011. Lipid droplets: size matters. Journal of Electron Microscopy, 60(Suppl.1): 101-116.

Tirawanchai, N., Homongkol, P., Chansriniyom, C., Somkasetrin, A., Jantaravinid, J., \& Kengkoom, K. 2019. Lipid-lowering effect of Phyllanthus embilica and Alpinia galangal extracts on Hepg2 cell line. PharmaNutrition 9(April), pp. 1-7.

Ullah, A., Munir, S., Mabkhot, Y., \& Badshah, S. L. 2019. Bioactivity profile of the diterpene isosteviol and its derivatives. Molecules 24(678): 1-24.

Wang, T., \& Butany, J. 2017. Pathogenesis of Atherosclerosis. Diagnostic Histopathology 23(11): 473-478.

Yang, L., Li, Z., Song, Y., Liu, Y., Zhao, H., Liu, Y., Zhang, T., Yuan, Y., Cai, X., Wang, S., Wang. P., Gao, S., Li, L., Li, Y., \& Yu, C. 2019. Study on urine metabolic profiling and pathogenesis of hyperlipidemia. Clinica Chimica Acta, 495: 365-373. 